\title{
Change of asphaltene and resin properties after catalytic aquathermolysis
}

\author{
Yi Yufeng ${ }^{1}$, Li Shuyuan ${ }^{1}$, Ding Fuchen ${ }^{1,2 *}$ and Yu Hang ${ }^{1}$ \\ ${ }^{1}$ School of Chemical Science and Engineering, China University of Petroleum (Beijing), Beijing 102249, China \\ ${ }^{2}$ School of Chemical Engineering, Beijing Institute of Petrol-chemical Technology, Beijing 102617, China
}

\begin{abstract}
Resin and asphaltene were separated from Liaohe heavy oil. Catalytic aquathermolysis of asphaltene and resin was investigated by using water soluble catalysts $\left(\mathrm{NiSO}_{4}\right.$ and $\left.\mathrm{FeSO}_{4}\right)$ and oil soluble catalysts (nickel naphthenate and iron naphthenate). Before and after aquathermolysis, the properties of the resin and asphaltene was compared by means of ultimate analysis, vapor pressure osmometer (VPO) average molecular weight, X-ray diffraction (XRD), ${ }^{13} \mathrm{C}$ and ${ }^{1} \mathrm{H}$ nuclear magnetic resonance (NMR). The conversion sequence was as follows: No-catalyst $<\mathrm{NiSO}_{4}<\mathrm{FeSO}_{4}<$ nickel naphthenate $<$ iron naphthenate. In the presence of catalysts, the amount of $\mathrm{H}_{2}$ and $\mathrm{CO}$ increased significantly, while $\mathrm{H}_{2} \mathrm{~S}$ in the gas product decreased. The molecular weight of asphaltene and resin increased after reaction without catalyst. But the catalysts restrained this trend. The $\mathrm{H} / \mathrm{C}$ ratio of asphaltene and resin decreased after reaction. From the results of average structural parameters and molecular weight, it was found that asphaltene and resin were partly aggregated after aquathermolysis.
\end{abstract}

Key words: Asphaltene, resin, aquathermolysis, molecular weight, catalyst

\section{Introduction}

The supply of conventional light crude oil is inevitably and inexorably decreasing worldwide and its quality becomes poorer than ever. At the same time, extremely large reserves of heavy crude oil and bitumen are found at home and abroad. However, the high contents of sulfur, nitrogen, oxygen and metals, as well as the high viscosity and density of the heavy crude oil and bitumen make its production and utilization difficult. Steam stimulation is the most popular and effective technology to recover heavy oil. During steam injection, a down hole upgrading of heavy crude oil, named aquathermolysis firstly by Hyne, would take place, resulting in great decrease of its viscosity and improvement of its quality (Hyne and Greidanus, 1982). Since then, underground upgrading of heavy crude oil has been widely studied due to its great advantages compared with the aboveground upgrading. Great progress was made in searching for suitable catalysts (Cesar et al, 2003; Li et al, 2007), in selecting hydrogen donors (Ovalles, 2003; Ovalles, 1995), and in interpreting reaction mechanism (Cesar et al, 2003; Richard et al, 2000; Beigrave et al, 1997). According to the literature, almost all of the scientists have directly used heavy crude oil to carry out their work (Fan et al, 2001; Mujiea et al, 2000; Fan et al, 2007). Because of the complicated composition of heavy crude oil, it is difficult to understand the reaction mechanism of aquathermolysis and to select appropriate catalysts if the mutual influence of its components is not eliminated. Nevertheless, it is impossible and unnecessary

*Corresponding author. email: dingfuchen@bipt.edu.cn

Received October 8, 2008 to separate the heavy crude oil into single components for research.

In the exploitation and utilization of heavy oil resources, many problems appear due to asphaltene and resin, which tend to associate and precipitate out from the oil system (Nikookar et al, 2008), resulting in deposition and plugging oil wells, hence causing a number of costly operational problems to oil producers (Abdulrazag et al, 2007; Mansoori et al, 2007). Asphaltene and resin are also the primary cause of catalyst poisoning and of reducing the activity of hydrotreating catalysts due to coking on the catalyst surface and pore-mouth blocking (Takeshige et al, 2005). Much work on heavy oil upgrading has been aimed at asphaltene (Zhang et al, 2005; Enkhsaruul and Yasuo, 2003; Fernando and Jorge, 2005; Thierry et al, 2008; Wang and Edward, 2003). There is no doubt that heavy oil aquathermolysis will ultimately focus on asphaltene and resin. To study the aquathermolysis of heavy oil and its property change, a heavy oil sample, from Liaohe Oilfield, Northeast China, was separated into four groups, namely saturates, aromatics, resin and asphaltene, according to their polarity. In this paper, aquathermolysis of asphaltene and resin, using dissolved nickel and iron compounds as catalyst, were carried out to investigate the reaction behavior and their property change after reaction.

\section{Experimental}

\subsection{Separation of asphaltene and resin}

The contents of saturates, aromatics, resin and asphaltene in Liaohe heavy crude oil are $25.35 \%, 19.17 \%, 53.14 \%$, $2.34 \%$, respectively. The heavy crude oil contains $2.40 \%$ 
of moisture and has a density of $1.0006 \mathrm{~g} \cdot \mathrm{cm}^{-3}$ at $20{ }^{\circ} \mathrm{C}$. The ultimate analysis and simulation distillation results are shown in Table 1 and Table 2. Liquid-solid adsorption chromatography was used to separate the heavy crude oil. About 20 grams of the heavy oil was dissolved in 400 $\mathrm{mL}$ pentane, and then heated and boiled for 1 hour under reflux. The mixture of heavy oil and pentane was filtered on Whatman filter paper (British Whatman Co., maximum filtering diameter 6-12 $\mu \mathrm{m})$. Remains on the filter paper were enwrapped by more filter paper and extracted in a Soxhlet extractor using $300 \mathrm{~mL}$ of pentane for $12 \mathrm{hrs}$. Asphaltene was obtained on the filter paper. Neutral alumina with a size of 100-200 mesh was calcined at $550{ }^{\circ} \mathrm{C}$ for 4 hours. And then about $1 \%$ (by weight) of water was added to the alumina to lower its adsorption ability. The alumina was filled into a glass column shaped like a condensor with a stopcockcontrolled outlet on the bottom like a separating funnel. The column was about $2 \mathrm{~cm}$ in diameter and $2 \mathrm{~m}$ long. In its interlayer $50{ }^{\circ} \mathrm{C}$ water was circulated. The remaining part of the heavy oil was dissolved in light naphtha and poured into the glass column. The column was washed using different solvents, including light naphtha, benzene, and ethanolbenzene mixture. Through the operation, saturates, aromatics and resin were washed down in turn. After removal of solvent through evaporation, saturates, aromatics and resin were obtained.

Table 1 Ultimate analysis and metal contents of the Liaohe heavy crude oil

\begin{tabular}{ccccccccccc}
\hline \multicolumn{4}{c}{ Ultimate analysis, $\%$} & & \multicolumn{5}{c}{ Metal, $\mu \mathrm{g} \cdot \mathrm{g}^{-1}$} \\
\hline $\mathrm{C}$ & $\mathrm{H}$ & $\mathrm{O}$ & $\mathrm{N}$ & $\mathrm{S}$ & $\mathrm{Ca}$ & $\mathrm{Ni}$ & $\mathrm{Fe}$ & $\mathrm{Mn}$ \\
84.81 & 12.05 & 2.1 & 0.55 & 0.49 & 524 & 125 & 48 & 18 \\
\hline
\end{tabular}

Table 2 Simulation distillation of the Liaohe heavy crude oil (IBP: Initial Boiling Point)

\begin{tabular}{ccccccccc}
\hline Cut, vol\% & IBP & 10 & 20 & 30 & 40 & 50 & 60 & 67 \\
\hline$T,{ }^{\circ} \mathrm{C}$ & 213 & 318 & 378 & 428 & 455 & 480 & 512 & 537 \\
\hline
\end{tabular}

\subsection{Catalytic aquathermolysis of asphaltene and resin}

About $5 \mathrm{~g}$ asphaltene or resin was added into a $500 \mathrm{~mL}$ stainless-steel batch reactor equipped with a magnetic stirrer. Fifty milliliters of cyclohexane was used as the hydrogen donor. It contained oil soluble catalyst, such as $0.1 \mathrm{wt} \%$ nickel naphthenate (abbreviated as NiN) or iron naphthenate (abbreviated as FeN). Then fifty milliliters water was added, which contained water soluble catalyst, such as $0.1 \mathrm{wt} \%$ nickel sulfate (abbreviated as $\mathrm{NiSO}_{4}$ ) or ferrous sulfate (abbreviated as $\mathrm{FeSO}_{4}$ ). Air in the reactor was purged with high purity nitrogen to avoid possible explosion risk. The reactor was stirred at $120 \mathrm{rpm}$ for $48 \mathrm{hrs}$ at $280{ }^{\circ} \mathrm{C}$. Then the reactor was cooled, and the oil and gas products were collected for analysis.

\subsection{Tests and analysis}

The obtained oil product sample was vacuum-dried at 80 ${ }^{\circ} \mathrm{C}$ for $24 \mathrm{hrs}$, and removing cyclohexane at the same time. The amount of gas product was calculated by weight loss $($ Gas $=100 \times[$ asphaltene $($ or resin $)$ reactant - weight of oil product]/asphaltene (or resin) reactant). The concentration of hydrogen in the gas product was analyzed by using GC7890 gas chromatography equipped with a thermal conductivity detector and 5A zeolite molecular sieve column. Nitrogen was used as carrier. The conditions for analysis were as follows: oven temperature $50{ }^{\circ} \mathrm{C}$, detector temperature $100{ }^{\circ} \mathrm{C}$, injector temperature $80{ }^{\circ} \mathrm{C}$, and bridge electric current of $120 \mathrm{~mA}$. The external standard method was used to calculate the content of hydrogen in the gas product. Other components in the gas product were analyzed on a Agilent 6890/5973 GC-MS with electronic ionization and mass spectroscopy detector. The GC column was an Abel AB-5MS $(60 \mathrm{~m} \times 0.25 \mathrm{~mm} \times 0.25 \mathrm{um})($ Abel Co., USA). High purity helium was used as carrier. About $2 \mathrm{~g}$ oil product samples were enwrapped in Whatman filter paper and extracted by $80 \mathrm{~mL}$ toluene in a Soxhlet extractor for 12 $\mathrm{h}$ to obtain the toluene insoluble fraction. The oil products were separated by liquid-solid adsorption chromatography as mentioned above to get the different SARA fractions (saturates, aromatics, resin and asphaltene). The separation was carried out on a small-scale glass column as described above. Conversion was calculated as follows: conversion $=100 \times$ reacted asphaltene (or resin)/asphaltene (or resin) reactant. Molecular weight was determined using a model 833 Vapor Pressure Osmometer made by UIC Inc., USA. Toluene was used as solvent and sucrose octaacetate as the standard substance with molecular weight of 678.6. Ultimate analysis was carried out by using a FLASH-EA1112 made by Thermo Fisher Scientific Inc., USA. XRD of asphaltene and resin was conducted using an XRD-7000 diffractometer (Shimadzu Co., Japan). ${ }^{13} \mathrm{C}$ and ${ }^{1} \mathrm{H}$ nuclear magnetic resonance was carried out on a Varian INOVA500 (Varian Co., USA).

\section{Results and discussion}

\subsection{Conversion of asphaltene (or resin) and its product composition}

Asphaltene and resin are thermally unstable. Different cracking reactions take place at temperatures. And the products would further be converted to coke through secondary reactions. The main reactions are as follows: breaking of $\mathrm{C}-\mathrm{C}, \mathrm{C}-\mathrm{H}$, metal- and heteroatom-linked bonds; aromatization, alkylation, condensation, and hydrogenation and dehydrogenation.

The results of aquathermolysis of asphaltene or resin are shown in Fig. 1 and Fig. 2. Aquathermolysis of asphaltene or resin took place even when no catalyst was present. Conversions of asphaltene and resin were about $3.8 \%$ and $8.1 \%$, respectively, in the absence of catalyst. In fact, the conversion used here is not the concept itself, since asphaltene would be converted into the other asphaltene with higher polarity. To some extent, it can be used to denote the decomposition degree of asphaltene and resin. The catalysts 
were obviously helpful to its conversion. The catalytic ability sequence was as follows: No-catalyst $<\mathrm{NiSO}_{4}<\mathrm{FeSO}_{4}<$ nickel naphthenate $<$ iron naphthenate. The conversion of asphaltene was $3.8 \%-14.9 \%$, while the conversion of resin was $8.1 \%$ $22.9 \%$. Oil soluble catalysts showed better catalytic ability than water soluble ones, which was in accordance with the results of Fan et al (2006).

Sergio et al (2006) reported that Fe directly interacted with heteroatoms $(\mathrm{N}, \mathrm{S})$ leading to the formation of metalasphaltene complexes, and the highest activity was found in $\mathrm{C}-\mathrm{S}$ bonds. Negative charges, in the presence of $\mathrm{H}_{2} \mathrm{O}$, will weaken the $\mathrm{Fe}-\mathrm{O}$ and $\mathrm{Fe}-\mathrm{N}$ bonds but reinforce $\mathrm{Fe}-\mathrm{S}$ ones. Enkhsaruul and Yasuo (2003) reported the cracking of petroleum asphaltene on a catalyst of $10 \mathrm{wt} \% \mathrm{Fe}$ supported on mesoporous molecular sieve (SBA-15) in a fixed bed reactor at $300{ }^{\circ} \mathrm{C}$ under atmospheric pressure $\mathrm{He}$. It is proved that $\mathrm{Fe}$ is an effective catalytic component for hydrotreating.

Iván et al (2005) used a quantum mechanics parametric method to investigate the interaction of metallic nickel, potassium, and water molecule with an asphaltene model molecule. It was found that there is a strong interaction between metallic nickel and nitrogen and sulfur atoms of asphaltene molecules, resulting in the formation of nickelasphaltene intermediate complexes. Nickel-asphaltene complexes could be able to dissociate water. In this case asphaltene molecules may be hydrogenated. Dispersed Ni and $\mathrm{Fe}$ participated in the aquathermolysis.

The presence of the catalyst decreased the mount of toluene insoluble. Asphaltene would be converted into gas products, saturates, aromatics, resin and toluene insoluble (coke). Resin would be converted into gas product, saturates, aromatics, asphaltene and toluene insoluble residue. According to the literature ( $\mathrm{Li}$ et al, 2007; Fan et al, 2007), the amount of asphaltene and resin in heavy oil decreased after aquathermolysis. From this fact people easily make the mistaken assumption that asphaltene and resin would be directly converted into gas product, saturates, aromatics and toluene insoluble residue. Because heavy crude oil is so complex in composition, it is impossible to find that asphaltene and resin could be converted into each other if heavy oil is used to carry out the aquathermolysis reaction. If asphaltene and resin are separately used to carry out the aquathermolysis reactions, their characteristics could be found out.

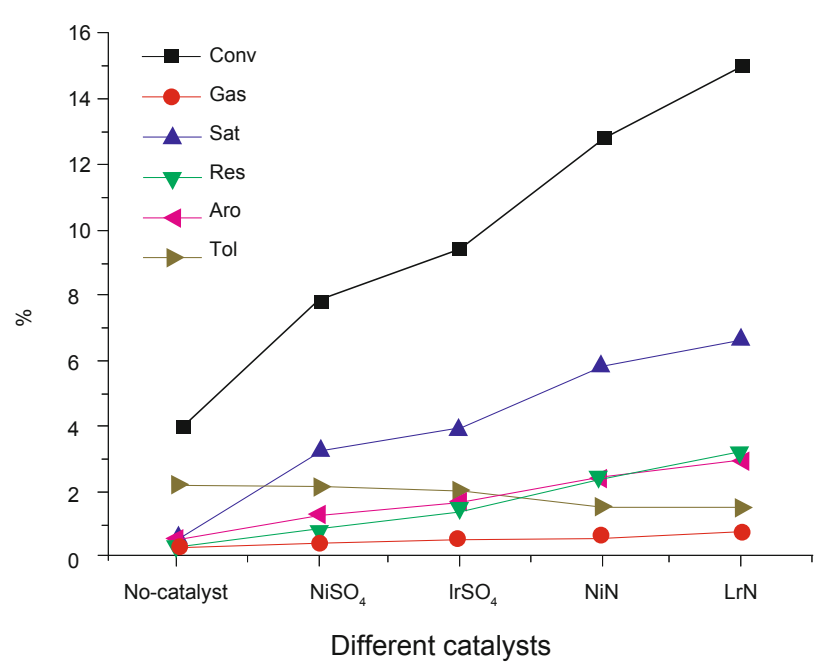

Fig. 1 Conversion of asphaltene and yields of different products in asphaltene aquathermolysis using different catalysts

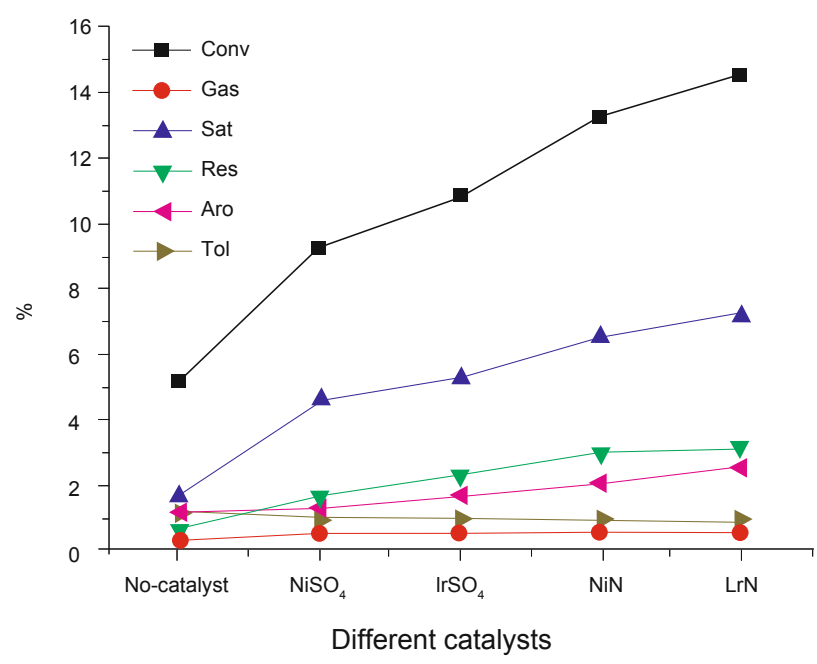

Fig. 2 Conversion of resin and yields of different products in resin aquathermolysis using different catalysts

\subsection{Composition of gas product}

The compositions of gas products of asphaltene and resin aquathermolysis are listed in Table 3 and Table 4. Obviously

Table 3 Composition of gas product of asphaltene aquathermolysis (vol\%)

\begin{tabular}{ccccccccc}
\hline Catalyst & $\mathrm{H}_{2}$ & $\mathrm{CO}$ & $\mathrm{CO}_{2}$ & $\mathrm{H}_{2} \mathrm{~S}$ & $\mathrm{CH}_{4}$ & $\mathrm{C}_{2} \mathrm{H}_{6}$ & $\mathrm{C}_{2} \mathrm{H}_{4}$ & $\mathrm{C}_{3}^{+}$ \\
\hline No-catalyst & 0 & 0 & 28.5 & 0.4 & 39.5 & 10.6 & 17.2 & 3.8 \\
$\mathrm{NiSO}_{4}$ & 1.3 & 0.5 & 21.7 & 0.3 & 43.0 & 13.6 & 14.8 & 4.8 \\
$\mathrm{FeSO}_{4}$ & 0.8 & 0.6 & 20.5 & 0.3 & 42.4 & 15.5 & 15.2 & 4.7 \\
$\mathrm{NiN}^{\mathrm{FeN}}$ & 1.5 & 1.2 & 22.8 & 0.2 & 40.4 & 18.5 & 12.4 & 3.0 \\
\hline
\end{tabular}


the catalyst increased the amount of $\mathrm{H}_{2}$ and $\mathrm{CO}$ in the gas product, while the content of $\mathrm{H}_{2} \mathrm{~S}$ decreased. Cesar et al (Cesar et al, 2003; Cesar et al, 1998) reported the aquathermolysis of Hamaca oil using dispersed molybdenum and iron catalysts. They found $\mathrm{MoS}_{2}$ and $\left(\mathrm{Fe}_{0.6} \mathrm{~V}_{0.4}\right) \mathrm{zS}$ (where $\mathrm{z}$ ranges from 0.8 to 0.9 ) in the coke. These two sulfides are the major active components for hydrotreating. It may be interpreted that the formation of sulfides promoted the hydrogen transfer reaction. There was very little hydrogen transfer reaction without catalyst. With the aid of the catalyst, $\mathrm{H}_{2}$ was produced by dissociation of water (Iván et al, 2005). The formation of the sulfides caused the decrease of $\mathrm{H}_{2} \mathrm{~S}$. Producing $\mathrm{CO}, \mathrm{CO}_{2}$ and benzene-insoluble simultaneously indicated that there existed thermal condensations reaction of asphaltene and resin.

Table 4 Composition of gas product of resin aquathermolysis (vol\%)

\begin{tabular}{|c|c|c|c|c|c|c|c|c|}
\hline Catalyst & $\mathrm{H}_{2}$ & $\mathrm{CO}$ & $\mathrm{CO}_{2}$ & $\mathrm{H}_{2} \mathrm{~S}$ & $\mathrm{CH}_{4}$ & $\mathrm{C}_{2} \mathrm{H}_{6}$ & $\mathrm{C}_{2} \mathrm{H}_{4}$ & $\mathrm{C}_{3}{ }^{+}$ \\
\hline No-catalyst & 0 & 0 & 26.5 & 0.4 & 40.2 & 24.4 & 5.4 & 3.1 \\
\hline $\mathrm{NiSO}_{4}$ & 0.9 & 1.5 & 21.4 & 0.2 & 42.7 & 22.8 & 7.7 & 2.8 \\
\hline $\mathrm{FeSO}_{4}$ & 0.5 & 1.0 & 18.8 & 0.3 & 41.7 & 25.2 & 9.4 & 3.1 \\
\hline $\mathrm{NiN}$ & 0.3 & 0.7 & 17.9 & 0.3 & 42.4 & 25.2 & 8.8 & 4.4 \\
\hline $\mathrm{FeN}$ & 0.3 & 0.8 & 15.8 & 0.3 & 43.5 & 26.8 & 8.7 & 3.8 \\
\hline
\end{tabular}

\subsection{Ultimate analysis}

The results of ultimate analysis are shown in Table 5. The catalyst used was iron naphthenate. After aquathermolysis, the $\mathrm{H} / \mathrm{C}$ ratio, oxygen and sulfur contents of asphaltene and resin decreased, which can be attributed to the release of the volatile components including $\mathrm{CO}, \mathrm{CO}_{2}, \mathrm{H}_{2} \mathrm{~S}$ and light alkanes. The asphaltene and resin had a relatively lower $\mathrm{H} /$ $\mathrm{C}$ ratio after the reaction due to dealkylation and increased condensed aromatic structures as well as the decreased branch-chains and aliphatic chain length.

Table 5 Results of ultimate analysis

\begin{tabular}{cccccc}
\hline Sample & $\mathrm{C} \%$ & $\mathrm{H} \%$ & $\mathrm{O} \%$ & $\mathrm{~N} \%$ & $\mathrm{~S} \%$ \\
\hline Resin before aquathermolysis & 85.25 & 10.45 & 2.41 & 1.04 & 0.85 \\
Resin after aquathermolysis & 85.82 & 9.84 & 2.38 & 1.33 & 0.63 \\
Asphaltene before aquathermolysis & 86.31 & 9.05 & 2.33 & 0.96 & 1.35 \\
Asphaltene after aquathermolysis & 87.16 & 8.62 & 2.11 & 1.04 & 1.07 \\
\hline
\end{tabular}

\subsection{Molecular weight}

The average molecular weight is an important parameter for characterization of asphaltene and resin. However, measurement of molecular weights (MW) of these components is difficult due to their high polydispersity, heterogeneity and easy formation of aggregates. The association state of these molecules is known to be very sensitive to experimental conditions, such as concentration, temperature and solvents. For this reason, interpretation of analytical results might be tedious, and the molecular weight of asphaltene measured by using different techniques can vary by several orders of magnitude (Sophie et al, 2006). In this study we used the vapor phase osmometer (VPO) method to estimate the MW of asphaltene and resin.
The molecular weights of asphaltene and resin before and after aquathermolysis reaction are shown in Fig. 3 and Fig. 4. Generally, dealkylation or shortening of the aliphatic chain would decrease the average molecular weight of asphaltene and resin. But the average molecular weight of asphaltene and resin increased after aquathermolysis (see Figs. 3 and 4 ). The average molecular weight of resin increased from 1,738 to 2,380 after aquathermolysis reaction without catalyst, while that of asphaltene from 2,710 to 3,510 . The reason might be that the partial association of these polar polynuclear aromatics resulted in increased polarity. The presence of catalyst restrained this increase. It might be that the formation of sulfide enhanced the hydrogen transfer reaction, thus holding back the aggregation of asphaltene and resin. Oil soluble catalysts had better restraining ability than 


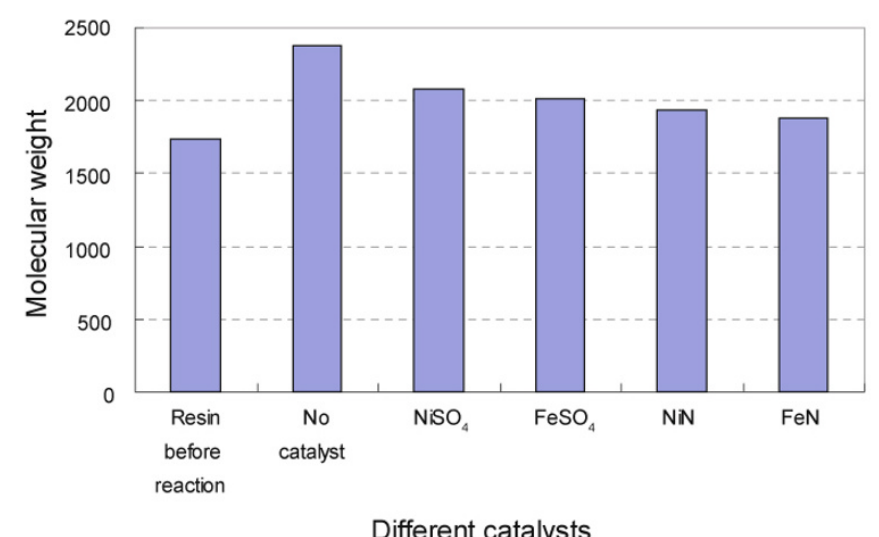

Different catalysts

Fig. 3 Molecular weight of resin before and after aquathermolysis using different catalysts

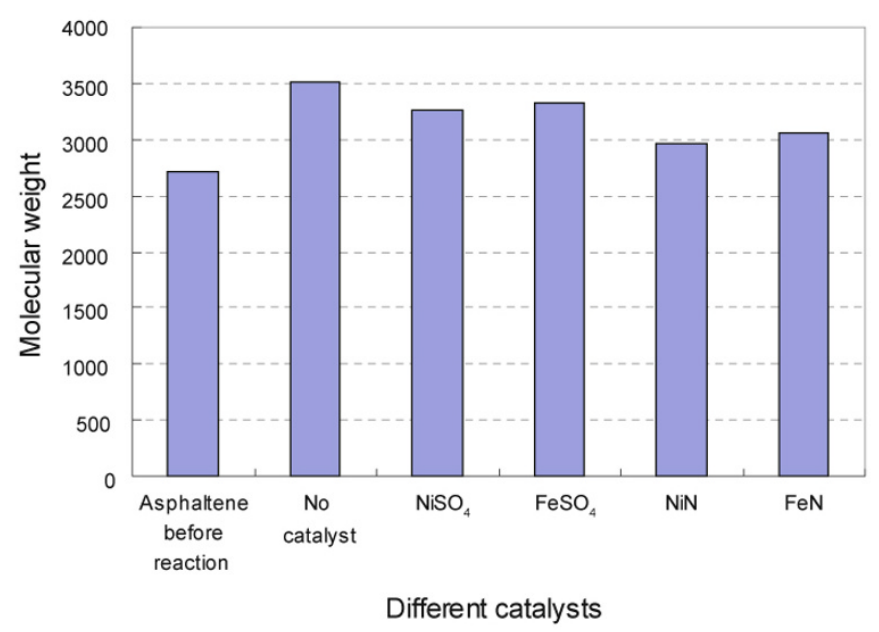

Fig. 4 Molecular weight of asphaltene before and after aquathermolysis using different catalysts

water soluble catalysts, because they participate much more readily in aquathermolysis.

\subsection{Results of XRD}

In the production and processing of heavy oil, many problems appear due to asphaltene and resin. So it is very important to know more information about the changes of property and structure of asphaltene and resin during processing. The information is very useful in developing upgrading technology and catalysts. The aromatic planar sheet structure of asphaltene and resin can be characterized by X-ray diffraction patterns of the peaks (002) and (110). In fact, one can estimate the diameter $L_{\mathrm{a}}$ of the aromatic planar sheet and the height $L_{\mathrm{c}}$ of the crystallite in the c-axis direction, using the Bragg and the Warren equations. From the equations, the following parameters can be determined:

Inter-sheet distance: $d_{\mathrm{m}}=\frac{\lambda}{2 \sin \theta}$

Inter-chain distance: $d_{\gamma}=\frac{5 \lambda}{8 \sin \theta}$

Diameter of the sheet: $L_{\mathrm{a}}=\frac{1.84 \lambda}{\omega \cos \theta}$
Height of the crystallite: $L_{\mathrm{c}}=0.9 \omega \cos \theta$

Average number of sheet per crystallite: $M_{e}=\frac{L_{\mathrm{c}}}{d_{\mathrm{m}}}+1$

where $\omega$ is the width of the band at a half maximum of the peak, $\lambda$ is the X-ray wavelength and $\theta$ is the diffraction angle (Bouhadda et al, 2007).

There are four peaks in the XRD patterns of asphaltene and resin. The peak $\gamma$ is thought to be the packing distance of saturated structures which arises from X-ray scattered by aliphatic chains or condensed saturated rings. The graphene peak or peak (002) comes from the diffraction of X-ray by the stacks of aromatic molecules (Mohammad, 2002). The peaks (100) and (110) in the diffraction of X-ray are from the in-plane structure of the aromatics. They correspond to the first and second nearest neighbors in the ring compounds. The broader the peaks in the XRD patterns, the more short-range order and less long-range order that exists in the structure type. In general, sharp narrow XRD pattern peaks are from highly crystalline samples with a high degree of long-range order. In the case of asphaltene and resin, there is good longrange order in some directions in the solid crystals, and only short-rang order in others. This is why there are some sharp peaks and one broad peak in all the diffraction patterns.

XRD patterns of asphaltene and resin before and after aquathermolysis are shown in Fig. 5 and Fig. 6. The crystal parameters of asphaltene and resin before and after aquathermolysis are shown in Table 6. After reaction, their crystal parameters were nearly unchanged. There was no

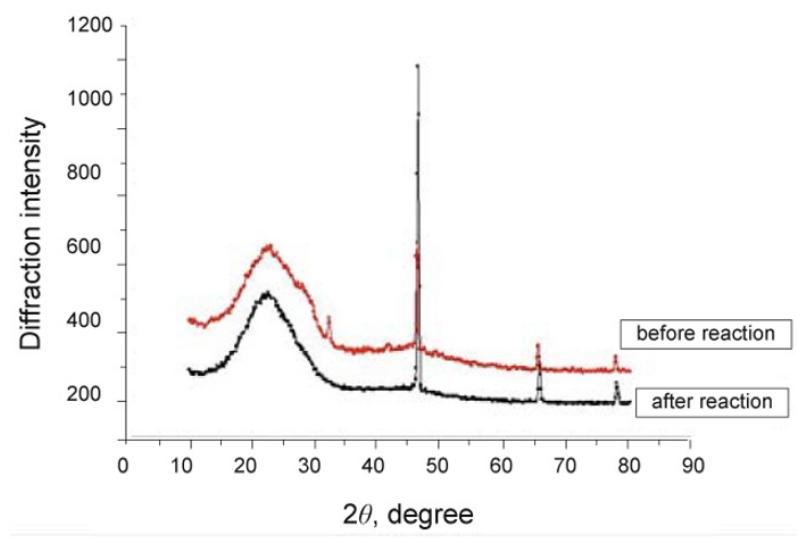

Fig. 5 XRD Profiles of Asphaltene before and after aquathermolysis

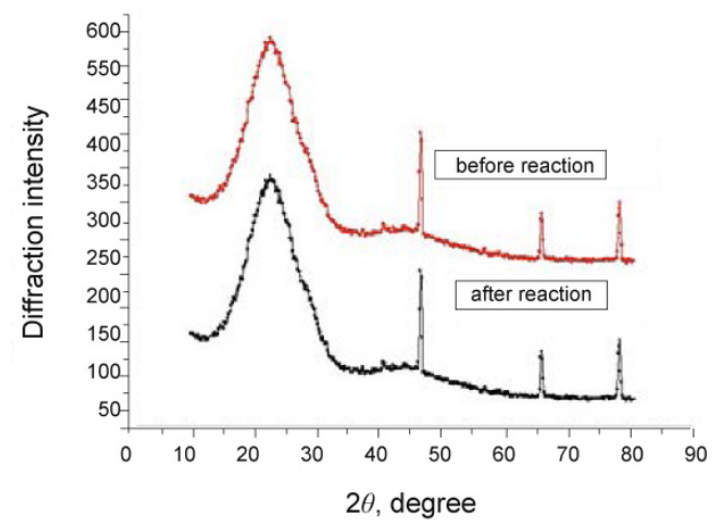

Fig. 6 XRD Profiles of Resin before and after aquathermolysis 
Table 6 Crystal parameters of asphaltene and resin

\begin{tabular}{|c|c|c|c|c|c|c|}
\hline & $(\AA)$ & $d_{\mathrm{m}}$ & $d_{\gamma}$ & $L_{\mathrm{a}}$ & $L_{\mathrm{c}}$ & $M_{\mathrm{e}}$ \\
\hline \multirow{2}{*}{ Asphaltene } & $\begin{array}{c}\text { Before } \\
\text { aquathermolysis }\end{array}$ & 3.6 & 4.5 & 13.7 & 22.4 & 7.2 \\
\hline & $\begin{array}{c}\text { After } \\
\text { aquathermolysis }\end{array}$ & 3.7 & 5.0 & 15.2 & 27.8 & 8.5 \\
\hline \multirow{2}{*}{ Resin } & $\begin{array}{c}\text { Before } \\
\text { aquathermolysis }\end{array}$ & 3.6 & 5.9 & 12.9 & 20.1 & 6.5 \\
\hline & $\begin{array}{c}\text { After } \\
\text { aquathermolysis }\end{array}$ & 3.7 & 6.8 & 14.4 & 26.7 & 8.2 \\
\hline
\end{tabular}

change in the layer distance between aromatic sheets, while the height of the crystallite increased. This implied the growth of the aromatic sheet after reaction.

\subsection{Average structural parameters}

Asphaltene and resin are very complex in molecular structure, and consist of polynuclear aromatics with alkyl side chains. It is difficult to know the exact molecular structure of asphaltene and resin because of their chemical complexity. Characterization of the average molecular structure of asphaltene and resin is the basic way to understand their functional properties. ${ }^{13} \mathrm{C}$ and ${ }^{1} \mathrm{H}$ nuclear magnetic resonance data is generally used to describe the total structure of asphaltene and resin (Dong et al, 2004; Hiroyuki and Fumio, 2000). NMR is used to interpret their structural parameters, such as aromaticity, averaged carbon number of each alkyl side chain, rate of substitution of aromatic rings, and aromatic ring number.

Combined with the results of ultimate analysis and molecular weight, the structural parameters of asphaltene and resin shown in Table 7 are calculated by using the ${ }^{13} \mathrm{C}$ and ${ }^{1} \mathrm{H}$ NMR data (Dong et al, 2004). After aquathermolysis, the aromaticity of asphaltene and resin increased. The aromatic ring number of asphaltene increased from 7.92 to 13.77 , while that of resin increased from 7.34 to 12.88 , indicating the aggregation of asphaltene and resin. The increase in aromaticity of asphaltene resulted from dealkylation.

Table 7 Results of average structural parameters

\begin{tabular}{ccccc}
\hline & $\begin{array}{c}\text { Asphaltene } \\
\text { before aquathermolysis }\end{array}$ & $\begin{array}{c}\text { Asphaltene } \\
\text { after aquathermolysis }\end{array}$ & $\begin{array}{c}\text { Resin before } \\
\text { aquathermolysis }\end{array}$ & $\begin{array}{c}\text { Resin } \\
\text { after aquathermolysis }\end{array}$ \\
\hline Aromatic carbon, \% & 0.52 & 0.55 & 0.47 & 0.52 \\
Naphthenic carbon, \% & 0.29 & 0.28 & 0.33 & 0.18 \\
Paraffinic carbon, \% & 0.19 & 0.17 & 0.2 & 12.88 \\
Aromatic ring number & 7.92 & 13.77 & 7.34 & 6.38 \\
Cycloparaffin ring number & 4.04 & 6.22 & 6.73 \\
\hline
\end{tabular}

\section{Conclusions}

To study the aquathermolysis of heavy oil, it is more target-oriented to use its asphaltene and resin than original heavy oil. In aquathermolysis of asphaltene and resin, catalytic activity sequence was as follows: Nocatalyst $<\mathrm{NiSO}_{4}<\mathrm{FeSO}_{4}<\mathrm{NiN}<\mathrm{FeN}$. Oil soluble catalysts had better catalytic ability than water soluble ones. In the presence of catalysts, the amount of $\mathrm{H}_{2}$ and $\mathrm{CO}$ increased significantly, while $\mathrm{H}_{2} \mathrm{~S}$ in the gas product decreased. From asphaltene aquathermolysis, gas product, saturates, aromatics, resin and toluene insoluble (coke) could be obtained. Resin could also be converted into gas product, saturates, aromatics, asphaltene and toluene insoluble. The chemical structures of asphaltene and resin after aquathermolysis were different from those of feedstock asphaltene and resin. Resin could be converted into asphaltene by aromatization and by dealkylation. In addition, aromatization and dealkylation of asphaltene could produce asphaltene products with higher polarity. The results of the average structural parameters and molecular weight showed that asphaltene and resin partly aggregated after aquathermolysis.

\section{Acknowledgements}

This work was financially supported by the Chinese Natural Science Foundation (No. 40472061), Funding Project for Academic Human Resources Development in Institutions of Higher Learning of Beijing Municipality (No. PXM2007014222-044654) and Funding Project of Organization Department of Beijing Municipal Party Committee (No. 20071D0500500163).

\section{References}

Abdulrazag Y. Z, Shedid A. S and Hassan A. A new technique for treatment of permeability damage due to asphaltene deposition using laser technology. Journal of Petroleum Science and Engineering. 2007. 59(3-4): 300-308

Beigrave J D M, Moore R G and Ursenbach M G. Comprehensive kinetic models for the aquathermolysis of heavy oils. The Journal of Canadian petroleum Technic.1997. 36(4): 38-44

Bouhadda Y, Bormann D, Sheu E, et al. Characterization of Algerian Hassi-Messaoud asphaltene structure using Raman spectrometry and X-ray diffraction. Fuel. 2007. 86: 1855-1864

Cesar O, Eduardo F and Alfredo M. Use of a dispersed iron catalyst for upgrading extra-heavy crude oil using methane as source of 
hydrogen. Fuel. 2003. 82: 887-892

Cesar O, Eduardo F, Alfredo M, et al. Use of a Dispersed Molybdenum Catalyst and Mechanistic Studies for Upgrading Extra-Heavy Crude Oil Using Methane as Source of Hydrogen. Energy Fuels. 1998. 12 (2): 379-385

Dong X G, Lei Q F and Yu Q S. NMR determination of petroleum asphaltenes and their model molecules evaluation. Journal of Fuel Chemistry and Technology. 2004. 32(6): 668-672 (in Chinese)

Enkhsaruul B and Yasuo O. Cracking behavior of asphaltene in the presence of iron catalysts supported on mesoporous molecular sieve with different pore diameters. Fuel. 2003. 82: 1571-1577

Fan H F, Li Z B and Liang T. Experimental study on using ionic liquids to upgrade heavy oil. Journal of Fuel Chemistry and Technology. 2007. 35(1): 32-35

Fan H F, Liu Y J and Zhong L G. Studies on the synergetic effects of mineral and steam on the composition changes of heavy oils. Energy Fuels. 2001. 15(6): 1475-1479

Fan Z X, Zhao F L, Wang J X, et al. Upgrading and viscosity reduction of super heavy oil by aquathermolysis with a hydrogen donor. Journal of Fuel Chemistry and Technology. 2006. 34(3): 316-318(in Chinese)

Fernando T and Jorge A. Kinetics of asphaltenes conversion during hydrotreating of Maya crude. Catalysis Today. 2005. 109: 99-103

Hiroyuki S and Fumio K. Structural change of petroleum asphaltenes and resins by hydrodemetallization. Energy \& Fuels. 2000. 14: 980985

Hyne J B and Greidanus J W. Aquathermolysis of heavy oil. Rev. Tec. Intevep. 1982. 2(2): 87-94

Iván M, Jesús J C D, Guaicaipuro R, et al. Theoretical study of catalytic steam cracking on an asphaltene model molecule. Journal of Molecular Catalysis A: Chemical. 2005. 227: 223-229

Li W, Zhu J H and Qi J H. Application of nano-nickel catalyst in the viscosity reduction of Liaohe extra-heavy oil by aqua-thermolysis. Journal of Fuel Chemistry and Technology. 2007. 35(2): 176-180

Mansoori G A, Vazquez D and Mojtaba S N. Polydispersity of heavy organics in crude oils and their role in oil well fouling. Journal of Petroleum Science and Engineering. 2007. 58(3-4): 375-390

Mohammad N S, Mohammad F A and John S. Use of X-ray diffraction in assessing the aging pattern of asphalt fractions. Fuel. 2002. 81: $51-58$

Mujiea V, Nieto P, Puerta L, et al. Caging of molecules by asphaltenes-A model for free radical preservation in crude oils. Energy \& Fuel. 2000. 14(3): 632-639

Nikookar M, Pazuki G R, Omidkhah M R, et al. Modification of a thermodynamic model and an equation of state for accurate calculation of asphaltene precipitation phase behavior. Fuel. 2008. 87(1): 85-91

Ovalles C, Hamana A, Rojas I, et al. Upgrading of extra-heavy crude oil by direct use of methane in the presence of water. Fuel. 1995. 74(8): $1162-1168$.

Ovalles C, Vallejos C, Vasquez T, et al. Downhole upgrading of extraheavy crude oil using hydrogen donors and methane under steam injection conditions. Petroleum Science and Technology. 2003. 21(1-2): 255-274

Richard. P. D, William C M C and Murray R G. Thermal cracking of Athabasca bitumen :influence of steam on reaction chemistry. Energy \& Fuels. 2000. 14(2): 671-676

Sergio R, Iván M, Morella S, et al. Theoretical modeling of molecular interactions of iron with asphaltenes from heavy crude oil. Journal of Molecular Catalysis A: Chemical. 2006. 246: 146-153

Sophie B, Cristiane C G, Koyo N, et al. Molecular size and weight of asphaltene and asphaltene solubility fractions from coals, crude oils and bitumen. Fuel. 2006. 85: 1-11

Takeshige T, Hidehiro H and Takami K. Development of a new hydrodemetallization catalyst for deep desulfurization of atmospheric residue and the effect of reaction temperature on catalyst deactivation. Catalysis Today. 2005. 104(1): 76-85

Thierry G, Pierre D F, Isabelle M, et al. Studies on the evolution of asphaltene structure during hydroconversion of petroleum residues . Catalysis Today. 2008. 130: 429-438

Wang J S and Edward J. A study of thermal-cracking behavior of asphaltenes. Chemical Engineering Science. 2003. 58(1): 157-162

Zhang L L, Yang G H and Que G H. The conglomerating characteristics of asphaltenes from residue during thermal reaction. Fuel. 2005. 84(7-8): 1023-1026

(Edited by Zhu Xiuqin) 